\title{
Balance rehabilitation using custom-made Wii Balance Board exercises: clinical effectiveness and maintenance of gains in an acquired brain injury population
}

\begin{abstract}
Balance disorders are a common impairment after an acquired brain injury (ABI). Neurorehabilitation programs focus on the rehabilitation of balance skills to enhance patients' self-dependency. The Wii Balance Board has been adopted with rehabilitative purposes due to its low cost and widespread battery of exercises. However, this entertainment system is oriented to healthy people and cannot easily adapt to the patient's motor (and possible cognitive) deficits. The objective of this study was two-fold: a) to study whether custom-made rehabilitative exercises on a force platform could improve the balance condition of ABI patients compared with conventional physical therapy programs; and b) to study if their clinical effects persisted in absence of the virtual training. To prove the first hypothesis, a randomized controlled trial (RCT) was carried out involving $17 \mathrm{ABI}$ participants (control group: 8 participants; experimental group: 9 participants). To prove the second hypothesis a follow-up study (FUS) was carried out involving 7 ABI participants. The participants of both studies underwent 201 -h sessions, from 3 to 5 sessions per week. The participants were assessed at the beginning and at the end of the treatment (RCT, FUS) and 1 month after the therapy (FUS). Significant improvements were detected in some scales for those participants who underwent the virtual therapy (RCT). The effects persisted over time (FUS). Balance training
\end{abstract}

*Corresponding author: Roberto Lloréns, MSc, Instituto Interuniversitario de Investigación en Bioingeniería y Tecnología Orientada al Ser Humano, Universitat Politècnica de València, Camino de Vera s/n, 46022 Valencia, Spain,

E-mail: rllorens@labhuman.i3bh.es

Sergio Albiol and José-Antonio Gil-Gómez: Instituto de Automática e Informática Industrial, Universitat Politècnica de València, Valencia, Spain

Mariano Alcañiz: Instituto Interuniversitario de Investigación en Bioingeniería y Tecnología Orientada al Ser Humano, Universitat Politècnica de València, Valencia, Spain

Carolina Colomer and Enrique Noé: Servicio de Neurorrehabilitación y Daño Cerebral de los Hospitales NISA, Fundación Hospitales NISA, Valencia, Spain through low-cost force platforms and custom-made exercises can provide lasting clinical benefits to ABI chronic patients when compared to conventional treatments.

Keywords: acquired brain injury; balance; posturography; virtual rehabilitation; Wii Balance Board.

DOI 10.1515/ijdhd-2014-0323

Received April 8, 2013; accepted May 23, 2013; previously published online July 19, 2014

\section{Introduction}

There are multiple pathologies, such as acquired brain injury (ABI), multiple sclerosis, Parkinson's and Alzheimer's disease or vestibular disorders that induce balance complications [1], which can directly or indirectly affect the performance of the activities of daily living [2]. The rehabilitation strategies consider specialized programs to regain balance and enhance the patients' self-dependency. The improvement of the balance control has been traditionally assessed by functional scales and posturography studies, which aim to objectively quantify the balance condition through measurements of the center of pressure (COP). The COP has proven to be a relevant indicator of the patients' balance condition [3, 4]. Given that the COP can be directly estimated from the individuals' weight distribution on a force platform, several systems based on force plates have come onto the market in recent years. Although their initial purpose was to provide therapists with new assessment tools, some of these systems also provide rehabilitation exercises.

The Nintendo ${ }^{\circledast}$ Wii Balance Board (WBB), a peripheral of the Nintendo ${ }^{\circledR}$ Wii gaming system launched for entertainment purposes, has achieved great acceptance in the clinical community, since its performance can be compared with professional systems with significantly lower 
costs [5]. In addition, the WBB is portable, works wirelessly, and not too time consuming to set up. There have been an increasing number of studies involving the WBB, and most of them use off-the-shelf games with balance rehabilitation purposes [6]. However, even though these games can be motivating, they are oriented to the entertainment of the healthy population and can require motor and cognitive skills that disabled individuals often lack. The studies involving custom-made rehabilitative exercises are especially interesting [7], because they are specifically designed with rehabilitative purposes, can provide patients with contents adapted to their particular motor and cognitive impairments, and can provide therapists with objective data of the evolution of the patients.

In previous studies, we have designed and studied the clinical effectiveness of the easy balance virtual rehabilitation system (eBaViR), a set of custom-made WBB exercises for chronic ABI patients, with promising results [7]. The objective of this paper is to present our experiences and conclusions in the design and the validation of the adapted balance rehabilitation exercises involving the WBB.

\section{Methods}

All the clinical data presented here are extracted from two studies that involve chronic ABI patients of the neurorehabilitation service of Hospital NISA Valencia al Mar. The first study was conducted in 2010. The second study is currently being carried out. Both studies have the same inclusion/exclusion criteria. The inclusion criteria were as follows: 1 ) age $\geq 16$ years and $<80$ years; 2 ) chronicity $>6$ months; 3) absence of cognitive impairment (Mini-Mental State Examination [8] cut-off >23); 4) able to follow instructions; and 5) the ability to walk 10 meters indoors with or without technical orthopedic aids. The exclusion criteria were as follows: 1) patients with severe dementia or aphasia; 2) patients whose visual or hearing impairment does not allow the possibility of interaction with the system; 3) patients with hemispatial neglect; and 4) patients with ataxia or any other cerebellar symptom.

The objective of the first trial was to study whether custom-made rehabilitative exercises on a force platform could improve the balance condition of ABI patients compared with conventional physical therapy programs. To prove this hypothesis, a randomized controlled trial was carried out. The objective of the ongoing second trial is to study whether improved versions of the exercises have similar effects and if they persist in absence of the virtual training. In this case, a follow-up study was designed.

\section{First study}

The study evaluated the clinical effectiveness of the first prototype of the system. The first version of the eBaViR system included three exercises to train discrete displacements of the COP in the medial-lateral plane (air hockey), in the medial-lateral and anterior-posterior axis (Simon), and free displacements (balloon breaker) (Figure 1). After applying the inclusion/exclusion criteria, the final sample consisted of 20 patients, who were categorized depending on their falling risk and randomized to a control or an experimental group afterwards (Table 1). Three participants dropped out of the treatment.

All the participants underwent 20 1-h sessions, from 3 to 5 sessions per week. The control group underwent traditional physical therapy, while the experimental group used the developed system. The balance condition of all the participants was assessed by the Berg Balance Scale (BBS) [9], the Brunel Balance Assessment (BBA)
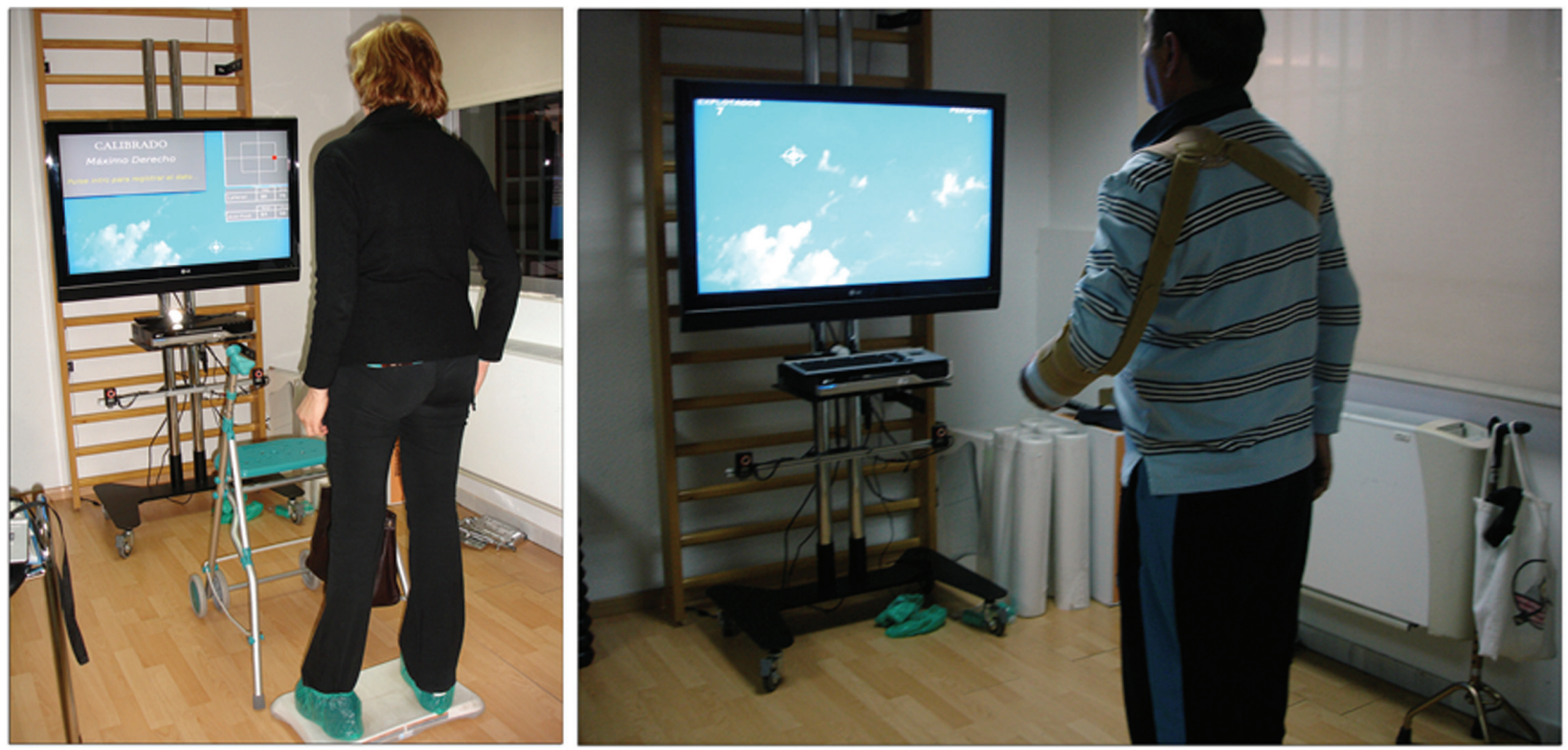

Figure 1 Patients interacting with the first prototype of the easy balance virtual rehabilitation system. 
Table 1 Characteristics of the participants of the first study.

\begin{tabular}{lrrr}
\hline Issue & Control group & $\begin{array}{r}\text { Experimental } \\
\text { group }\end{array}$ & Significance \\
\hline Gender, $\mathrm{n}$ & & $\mathrm{ns}(\mathrm{p}=0.858)$ \\
$\quad$ Male & $5(29.4 \%)$ & $6(35.3 \%)$ & \\
$\quad$ Female & $3(17.7 \%)$ & $3(17.7 \%)$ & \\
Age, years & $49.13 \pm 21.18$ & $45.78 \pm 15.38$ & $\mathrm{~ns}(\mathrm{p}=0.704)$ \\
Etiology, $\mathrm{n}$ & & & $\mathrm{ns}(\mathrm{p}=0.657)$ \\
$\quad \begin{array}{l}\text { Stroke } \\
\text { Traumatic brain }\end{array}$ & $5(29.4 \%)$ & $6(35.3 \%)$ & \\
$\begin{array}{l}\text { injury } \\
\text { Benign cerebral } \\
\text { neoplasm }\end{array}$ & $1(5.9 \%)$ & $2(11.8 \%)$ & \\
Time since injury, & $2(11.8 \%)$ & $1(5.9 \%)$ & \\
days & & & \\
\hline
\end{tabular}

Age and time since injury are defined in terms of mean and standard deviation. Etiology and gender are also expressed as a percentage of the total number of patients. ns, non-significant.

[10], and the Functional Reaches Test (FRT) [11] as well as by other more dynamic scales, including Timed Stair Test (TST) [12], the Stepping Test (ST) [13], the 1-min Walking Test (1MWT) [14], the 10-meter Walking Test (10MT) [15], the Time "Up and Go" Test (TUG) [15], and the 30-s Sit-to-Stand Test (30CST) [16].

\section{Second study}

The second study is currently being carried out to study the clinical effectiveness of the second version of the system and the maintenance of gains. The second version of the system included four exercises that required discrete displacements of the COP and two exercises that require free displacements, with versions for standing and sitting position. In addition, the system included exercises for training one-leg standing, stair climbing, one-foot rising and sit-to-stand transfer (Figure 2). To date, seven participants from an expected final sample of 21 chronic ABI patients completed the training with the virtual system (Table 2).

The participants also underwent 20 1-h sessions held three to five times per week. Each participant trained with the prescribed exercises that mostly fit their needs according to the therapists. A similar battery of balance scales and tests was administered to each participant at the beginning, at the end, and 1 month after the trial (follow-up assessment). Similar to the first study, each participant's condition was assessed with the BBS, the FRT, the ST, the TUG, and the 30CST.

\section{Results}

\section{First study}

No significant differences in demographical (age and gender) or clinical (chronicity, etiology, and laterality) variables at inclusion were detected between groups (Table 1). A repeated measures ANOVA revealed a significant time effect for the BBS, BBA, the standing FRT, the ST paretic, the STnon paretic, the 1MWT, the TUG and the 30CST (Table 3). No group effect was detected for any outcome, which confirmed the comparability of both groups. Finally, significant group-by-time interaction was detected in the scores of the BBS and the FRT in standing position.
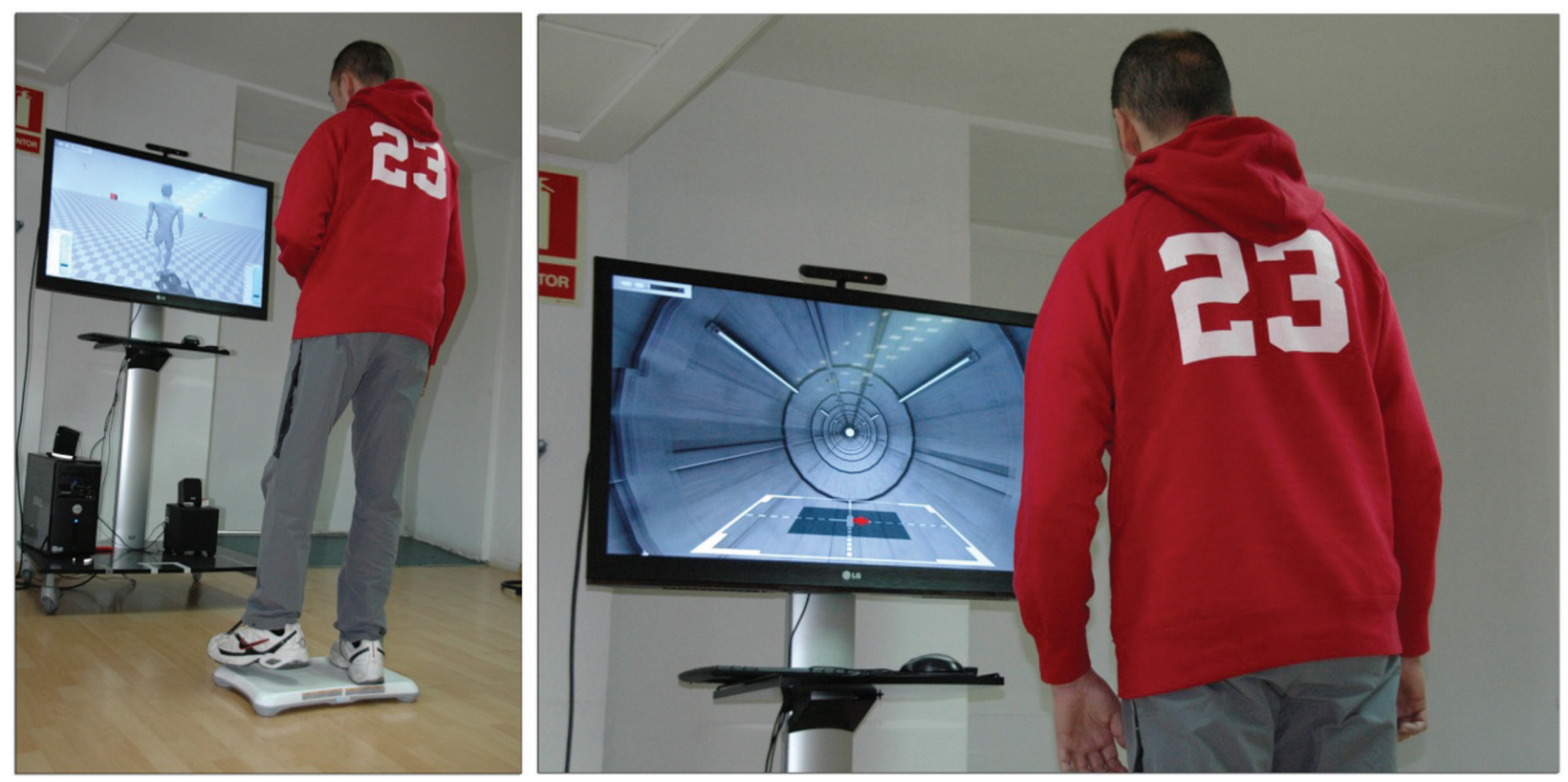

Figure 2 Patients interacting with the second prototype of the easy balance virtual rehabilitation system. 
Table 2 Characteristics of the participants of the second study.

\begin{tabular}{lr}
\hline Issue & Experimental group \\
\hline Gender, $\mathrm{n}$ & \\
$\quad$ Male & $6(85.7 \%)$ \\
$\quad$ Female & $1(14.3 \%)$ \\
Age, years & $48.08 \pm 16.03$ \\
Etiology, & \\
$\quad$ Stroke & $7(100.0 \%)$ \\
$\quad$ Traumatic brain injury & 0 \\
$\quad$ Benign cerebral neoplasm & 0 \\
Time since injury, days & $439.86 \pm 103.99$ \\
\hline
\end{tabular}

Age and time since injury are defined in terms of mean and standard deviation. Etiology and gender are also expressed as a percentage of the total number of patients.

\section{Second study}

A repeated measures ANOVA revealed significant time effect between the initial and the final assessment in all the measures. In addition, significant time effect was detected between the final and the follow-up assessment in the BBS, the ST non-paretic, the TUG, and the 30CST (Table 4).

\section{Discussion}

The statistical analyses showed that balance training through low-cost force platforms and custom-made exercises can provide clinical benefits to ABI chronic patients. Similar results were achieved in both studies (Table 5), confirming the effectiveness of both designs.

As shown in the first study, custom-made exercises on force platforms showed significant improvement in the BBS and in the FRT in standing position when compared with traditional physical therapy (Table 3 ). This can be due to the specificity of the exercises, which required repetitive displacements of the COP and the consequent adaptation of postural responses. The training of these tasks could have led to an improvement that, in turn, reflected in those scales. No significant group effect or group-by-time interaction was detected for either of the dynamic scales, suggesting that both groups improved in the same way. The system principally promoted the recovery of static balance, so the main improvement was detected in those scales and in tests that reflected these skills. No specific exercises for the dynamic skills of balance were included; consequently, the training did not provide special benefits to conventional physical training. However, several

Table 3 Clinical data of the first study.

\begin{tabular}{|c|c|c|c|c|}
\hline Scale & Group & Before treatment & After treatment & Significance \\
\hline \multirow[t]{2}{*}{ BBS } & Control & $45.38 \pm 7.35$ & $46.88 \pm 6.15$ & $\mathrm{~T}^{\mathrm{a}}(\mathrm{p}=0.000)$ \\
\hline & Trial & $41.22 \pm 10.57$ & $45.44 \pm 8.62$ & $\mathrm{GxT}^{\mathrm{b}}(\mathrm{p}=0.011)$ \\
\hline \multirow[t]{2}{*}{ BBA } & Control & $11.00 \pm 1.31$ & $11.13 \pm 1.13$ & $\mathrm{~T}^{\mathrm{b}}(\mathrm{p}=0.048)$ \\
\hline & Trial & $10.00 \pm 2.00$ & $10.33 \pm 2.18$ & \\
\hline \multirow[t]{2}{*}{ FRT standing, cm } & Control & $25.44 \pm 9.33$ & $25.63 \pm 9.74$ & $T^{a}(p=0.005)$ \\
\hline & Trial & $24.13 \pm 7.70$ & $27.25 \pm 10.38$ & $\mathrm{GxT}^{\mathrm{b}}(\mathrm{p}=0.011)$ \\
\hline \multirow[t]{2}{*}{ FRT sitting, cm } & Control & $40.06 \pm 6.87$ & $40.13 \pm 7.66$ & NS \\
\hline & Trial & $34.83 \pm 11.92$ & $37.78 \pm 12.34$ & \\
\hline \multirow[t]{2}{*}{ ST paretic, $n$} & Control & $6.57 \pm 2.30$ & $7.57 \pm 2.44$ & $\mathrm{~T}^{\mathrm{b}}(\mathrm{p}=0.021)$ \\
\hline & Trial & $6.75 \pm 3.58$ & $7.63 \pm 4.00$ & \\
\hline \multirow[t]{2}{*}{ ST non-paretic, $n$} & Control & $8.17 \pm 1.72$ & $9.50 \pm 3.39$ & $\mathrm{~T}^{\mathrm{b}}(\mathrm{p}=0.046)$ \\
\hline & Trial & $9.33 \pm 2.81$ & $10.50 \pm 3.02$ & \\
\hline \multirow[t]{2}{*}{ TST, s } & Control & $14.82 \pm 9.42$ & $12.13 \pm 4.94$ & NS \\
\hline & Trial & $15.38 \pm 9.69$ & $13.52 \pm 9.60$ & \\
\hline \multirow[t]{2}{*}{ 1MWT, m } & Control & $31.13 \pm 13.59$ & $36.38 \pm 15.39$ & $\mathrm{~T}^{\mathrm{a}}(\mathrm{p}=0.007)$ \\
\hline & Trial & $31.94 \pm 12.47$ & $42.69 \pm 20.43$ & \\
\hline \multirow[t]{2}{*}{ 10MT, s } & Control & $14.57 \pm 10.95$ & $14.07 \pm 9.02$ & NS \\
\hline & Trial & $13.47 \pm 8.29$ & $13.47 \pm 10.64$ & \\
\hline \multirow[t]{2}{*}{ TUG, s } & Control & $24.00 \pm 14.87$ & $19.52 \pm 10.91$ & $\mathrm{~T}^{\mathrm{a}}(\mathrm{p}=0.004)$ \\
\hline & Trial & $20.99 \pm 15.11$ & $18.69 \pm 13.43$ & \\
\hline \multirow[t]{2}{*}{ 30CST, n } & Control & $6.88 \pm 3.52$ & $8.50 \pm 3.12$ & $\mathrm{~T}^{\mathrm{a}}(\mathrm{p}=0.003)$ \\
\hline & Trial & $7.56 \pm 4.19$ & $9.00 \pm 4.74$ & \\
\hline
\end{tabular}

The results are given in terms of mean and standard deviation. G, group effect; T, time effect; GxT, group/time effect; NS, non-significant; ${ }^{\mathrm{a}} \mathrm{p}<0.01,{ }^{\mathrm{b}} \mathrm{p}<0.05, \mathrm{n}$, number of repetitions. 
Table 4 Clinical data of the second study.

\begin{tabular}{|c|c|c|c|c|}
\hline Scale & Initial assessment & Final assessment & Follow-up assessment & Significance \\
\hline BBS & $37.00 \pm 7.30$ & $42.00 \pm 6.73$ & $43.86 \pm 6.73$ & $\begin{array}{l}\mathrm{T} 1^{\mathrm{a}}(\mathrm{p}=0.002) \\
\mathrm{T} 2^{\mathrm{b}}(\mathrm{p}=0.011)\end{array}$ \\
\hline FRT standing, cm & $23.57 \pm 3.99$ & $28.64 \pm 8.12$ & $29.86 \pm 8.15$ & $\mathrm{~T} 1^{\mathrm{b}}(\mathrm{p}=0.049)$ \\
\hline ST paretic, $\mathrm{n}$ & $2.86 \pm 2.19$ & $5.14 \pm 1.95$ & $5.71 \pm 2.43$ & $\mathrm{~T} 1^{\mathrm{b}}(\mathrm{p}=0.012)$ \\
\hline ST non-paretic, $n$ & $5.14 \pm 2.79$ & $7.14 \pm 3.08$ & $8.43 \pm 3.31$ & $\begin{array}{l}\mathrm{T} 1^{\mathrm{b}}(\mathrm{p}=0.022) \\
\mathrm{T} 2^{\mathrm{a}}(\mathrm{p}=0.001)\end{array}$ \\
\hline TUG, s & $32.71 \pm 17.20$ & $28.05 \pm 16.08$ & $22.92 \pm 12.13$ & $\begin{array}{l}\mathrm{T} 1^{\mathrm{b}}(\mathrm{p}=0.045) \\
\mathrm{T} 2^{\mathrm{b}}(\mathrm{p}=0.021)\end{array}$ \\
\hline 30CST, n & $6.29 \pm 2.93$ & $10.14 \pm 4.67$ & $11.14 \pm 4.98$ & $\begin{array}{l}\mathrm{T} 1^{\mathrm{b}}(\mathrm{p}=0.012) \\
\mathrm{T} 2^{\mathrm{b}}(\mathrm{p}=0.018)\end{array}$ \\
\hline
\end{tabular}

The results are given in terms of mean and standard deviation. T1, time effect between the initial and the final assessment; T2, time effect between the final and the follow-up assessment; ${ }^{a} p<0.01,{ }^{b} p<0.05, n$, number of repetitions.

Table 5 Comparison of the results of both studies between the initial and the final assessments.

\begin{tabular}{lll}
\hline Scale & First design & Second design \\
\hline BBS & $\mathrm{T}^{\mathrm{a}}(\mathrm{p}=0.000)$ & $\mathrm{T}^{\mathrm{a}}(\mathrm{p}=0.002)$ \\
FRT standing & $\mathrm{T}^{\mathrm{a}}(\mathrm{p}=0.005)$ & $\mathrm{T}^{\mathrm{b}}(\mathrm{p}=0.049)$ \\
ST paretic & $\mathrm{T}^{\mathrm{b}}(\mathrm{p}=0.021)$ & $\mathrm{T}^{\mathrm{b}}(\mathrm{p}=0.012)$ \\
ST non-paretic & $\mathrm{T}^{\mathrm{b}}(\mathrm{p}=0.046)$ & $\mathrm{T}^{\mathrm{b}}(\mathrm{p}=0.022)$ \\
TUG & $\mathrm{T}^{\mathrm{a}}(\mathrm{p}=0.004)$ & $\mathrm{T}^{\mathrm{b}}(\mathrm{p}=0.045)$ \\
30CST & $\mathrm{T}^{\mathrm{a}}(\mathrm{p}=0.003)$ & $\mathrm{T}^{\mathrm{b}}(\mathrm{p}=0.012)$ \\
\hline
\end{tabular}

T, time effect; GxT, group/time effect; ${ }^{a} \mathrm{p}<0.01,{ }^{\mathrm{b}} \mathrm{p}<0.05$.

outcomes showed significant time effects of the training in scales that focused on balance skills during gait (e.g., 1MWT and TUG), or on other complex motor tasks (e.g., 30CST and ST).

According to the results of the second trial, the improvement between the initial and the final assessment lasted for a long time. Moreover, the participants showed significant improvements in the follow-up assessment in the scales of BBS, ST (in the non-paretic side), TUG, and 30CST. The training with the virtual system could have improved the balance condition that, in turn, supported the progressive improvement of these skills after the treatment, even in dynamic activities, as shown in the TUG.

However, these results must be considered cautiously, given the limitations of the studies and the sample. Nevertheless, the improvement of the patients who underwent virtual therapy in both studies was remarkable due to the chronicity of the sample $(478.00 \pm 324.77$ and $439.86 \pm 103.99$, respectively), which was higher that than the 6-month period traditionally considered as the period with maximum recovery (i.e., where spontaneous recovery takes place) [17].
Acknowledgments: This study was funded in part by Ministerio de Educación y Ciencia Spain, Projects Consolider-C (SEJ2006-14301/PSIC), "CIBER of Physiopathology of Obesity and Nutrition, an initiative of ISCIII", and the Excellence Research Program PROMETEO (Generalitat Valenciana. Conselleria de Educación, 2008-157).

\section{References}

1. Cheng Y-Y, Hsieh W-L, Kao C-L, Chan R-C. Principles of rehabilitation for common chronic neurologic diseases in the elderly. J Clin Gerontol Geriatr 2012;3:5-13.

2. Tyson SF, Hanley M, Chillala J, Selley AB, Tallis RC. The relationship between balance, disability, and recovery after stroke: predictive validity of the Brunel Balance Assessment. Neurorehabil Neural Repair 2007;21:341-6.

3. Ruhe A, Fejer R, Walker B. Center of pressure excursion as a measure of balance performance in patients with non-specific. low back pain compared to healthy controls: a systematic review of the literature. Eur Spine J 2011;20:358-68.

4. Terry K, Gade VK, Allen J, Forrest GF, Barrance P, Edwards WT. Cross-correlations of center of mass and center of pressure displacements reveal multiple balance strategies in response to sinusoidal platform perturbations. J Biomech 2011;44:2066-76.

5. Clark RA, Bryant AL, Pua Y, McCrory P, Bennell K, Hunt M. Validity. and reliability of the Nintendo Wii Balance Board for assessment. of standing balance. Gait Posture 2010;31:307-10.

6. Sugarman $\mathrm{H}$, Weisel-Eichler A, Burstin A, Brown R, editors. Use of the Wii Fit system for the treatment of balance problems in the elderly: a feasibility study. Virtual Rehabilitation International Conference, 2009 June 29-July 22009.

7. Gil-Gomez JA, Llorens R, Alcaniz M, Colomer C. Effectiveness of a Wii balance board-based system (eBaViR) for balance rehabilitation: a pilot randomized clinical trial in patients with acquired. brain injury. J Neuroeng Rehabil 2011;8:30.

8. Folstein MF, Folstein SE, McHugh PR. "Mini-mental state”. A practical method for grading the cognitive state of patients for the clinician. J Psychiatr Res 1975;12:189-98. 
9. Berg KO, Wood-Dauphinee SL, Williams JI, Maki B. Measuring balance in the elderly: validation of an instrument. Can J Public Health 1992;83 (Suppl 2):S7-11.

10. Tyson SF, DeSouza LH. Development of the brunel balance assessment: a new measure of balance disability post stroke. Clin Rehabil 2004;18:801-10.

11. Duncan PW, Weiner DK, Chandler J, Studenski S. Functional reach: A new clinical measure of balance. J Gerontol 1990;45:M192-7.

12. Perron M, Malouin F, Moffet $\mathrm{H}$. Assessing advanced locomotor recovery after total hip arthroplasty with the timed stair test. Clin Rehabil 2003;17:780-6.

13. Fujisawa H, Takeda R. A new clinical test of dynamic standing balance in the frontal plane: the side-step test. Clin Rehabil 2006;20:340-6.
14. McDowell BC, Kerr C, Parkes J, Cosgrove A. Validity of a 1 minute walk test for children with cerebral palsy. Dev Med Child Neurol 2005;47:744-8.

15. Steffen TM, Hacker TA, Mollinger L. Age- and gender-related test performance in community-dwelling elderly people: Six-Minute Walk Test, Berg Balance Scale, Timed Up \& Go Test, and gait speeds. Phys Ther 2002;82:128-37.

16. Verschuren O, Ketelaar M, Takken T, Van Brussel M, Helders PJ, Gorter JW. Reliability of hand-held dynamometry and functional strength tests for the lower extremity in children with cerebral palsy. Disabil Rehabil 2008;30:1358-66.

17. Jorgensen HS, Nakayama H, Raaschou HO, Vive-Larsen J, Stoier M, Olsen TS. Outcome and time course of recovery in stroke. Part II: Time course of recovery. The Copenhagen Stroke Study. Arch Phys Med Rehabil 1995;76:406-12. 